\title{
Overexpression and pre-treatment of recombinant human Secretory Leukocyte Protease Inhibitor (rhSLPI) reduces an in vitro ischemia/reperfusion injury in rat cardiac myoblast $(\mathrm{H} 9 \mathrm{c} 2)$ cell
}

https://doi.org/10.1515/bmc-2018-0004

received February 17, 2018; accepted April 5, 2018.

\begin{abstract}
One of the major causes of cardiac cell death during myocardial ischemia is the oversecretion of protease enzymes surrounding the ischemic tissue. Therefore, inhibition of the protease activity could be an alternative strategy for preventing the expansion of the injured area. In the present study, we investigated the effects of Secretory Leukocyte Protease Inhibitor (SLPI), by means of overexpression and treatment of recombinant human SLPI (rhSLPI) in an in vitro model. Rat cardiac myoblast $(\mathrm{H} 9 \mathrm{c} 2)$ cells overexpressing rhSLPI were generated by gene delivery using pCMV2-SLPI-HA plasmid. The rhSLPIH9c2 cells, mock transfected cells, and wild-type (WT) control were subjected to simulated ischemia/reperfusion (sI/R). Moreover, the treatment of rhSLPI in H9c2 cells was also performed under sI/R conditions. The results showed that overexpression of rhSLPI in H9c2 cells significantly reduced sI/R-induced cell death and injury, intracellular ROS level, and increased Akt phosphorylation, when compared to WT and mock transfection ( $\mathrm{p}<0.05)$. Treatment of rhSLPI prior to sI/R reduced cardiac cell death
\end{abstract}

\footnotetext{
*Corresponding author: Sarawut Kumphune, Biomedical Research Unit in Cardiovascular Sciences (BRUCS), Faculty of Allied Health Sciences, Naresuan University, Phitsanulok, 65000, Thailand; Department of Medical Technology, Faculty of Allied Health Sciences, Naresuan University, Phitsanulok, 65000, Thailand, E-mail: sarawutk@nu.ac.th

Eakkapote Prompunt, Nitirut Nernpermpisooth, Jantira Sanit: Biomedical Research Unit in Cardiovascular Sciences (BRUCS), Faculty of Allied Health Sciences, Naresuan University, Phitsanulok, 65000, Thailand

Eakkapote Prompunt, Jantira Sanit: Graduate program in Biomedical Sciences, Faculty of Allied Health Sciences, Naresuan University, Phitsanulok, 65000, Thailand Nitirut Nernpermpisooth: Department of Cardio-Thoracic Technology, Faculty of Allied Health Sciences, Naresuan University, Phitsanulok, 65000, Thailand
}

and injury, and intra-cellular ROS level. In addition, 400 $\mathrm{ng} / \mathrm{ml}$ rhSLPI treatment, prior to sI, significantly inhibited p38 MAPK phosphorylation and rhSLPI at 400-1000 ng/ $\mathrm{ml}$ could increase Akt phosphorylation.

Keywords: myocardial ischemia; secretory leukocyte protease inhibitor (SLPI); ischemia/reperfusion injury (I/R); SLPI overexpression; p38 MAPK.

\section{Introduction}

Ischemic heart disease (IHD) is the most common cause of death worldwide, even though there have been advances in both knowledge and technology. In addition, IHD is predicted to still be a serious cause of death in the future $[1,2]$. IHD is the condition in which the coronary artery is severelyblocked, resulting in insufficient blood and oxygen supply to the region of the myocardium that is supplied by the blocked artery [3]. If severe ischemia continues, the loss of structural integrity of cardiomyocytes could lead to irreversible injury and necrosis [3]. This condition is known as myocardial infarction. The most effective method for treating IHD is returning blood flow to the ischemic region again [4]. This method is called "reperfusion" [4]. However, the reperfusion itself has been known to aggravate myocardial injury, referred to as "reperfusion injury" [4]. One of the key mechanisms of cardiac cell death during myocardial $\mathrm{I} / \mathrm{R}$ injury is overproduction of protease enzymes, which could be secreted not only from infiltrated leukocytes but also cardiomyocytes and cardiac fibroblast [5-7]. These protease enzymes cause cellular necrosis within and around the ischemic area [5-7]. Therefore, prevention or attenuation of the protease enzyme activity caused by myocardial I/R injury is one of the most promising therapeutic targets for IHD.

Theeffectsof proteaseinhibitorshavebeeninvestigated over the past year on post-ischemic inflammation. 
Among protease inhibitors, secretory leukocyte protease inhibitors (SLPIs) seem to have the broadest and the most promising option for myocardial I/R injury [8]. SLPI is an $11.7 \mathrm{kDa}$ cationic non-glycosylated protein and belongs to the whey acidic protein (WAP) family [9-11]. The SLPI has been known to inhibit many leukocyte serine proteases including trypsin and chymotrypsin from pancreatic acinar cell, elastase and cathepsin $\mathrm{G}$ from neutrophil, as well as chymase from mast cells [10-12]. SLPI is the first line protein for defense against infections, including viruses, bacteria, and fungi by direct and indirect mechanisms [10]. In addition, SLPI also controls the effect of pro-inflammatory mediators resulting in a reduction of excessive host tissue damage by many proteolytic enzymes secreted during inflammation [10]. Therefore, SLPI could have therapeutic potential for IHD.

In 2008, Scheeberger et al. reported the effects of recombinant human SLPI(rhSLPI) in ischemia/reperfusion injury during cardiac transplantation [13]. They found that when the rhSLPI was added to the cold-preservative solution, the cardiac score of the transplanted heart was improved and the protease enzyme expression in the heart was decreased [13]. The rhSLPI plays a crucial role in early myocardial performance and post-ischemic inflammation after cardiac transplantation [13]. Therefore, rhSLPI could possibly be a promising target protecting the heart from ischemia/reperfusion injury. However, the effects of SLPI on myocardial ischemic/reperfusion injury have not been investigated. Since SLPI is less expressed in cardiac cells, the primary aim of this study was to investigate the effects of overexpression of SLPI in rat cardiac myoblast (H9c2) and its roles during ischemia reperfusion. In addition, we aim to measure the effect of recombinant human SLPI treatment on H9c2 cells prior to ischemic/reperfusion injury, for a more practical therapeutic approach.

\section{Materials and Methods}

\section{Chemical and reagent}

pCMV2-SLPI-HA and pCMV2-Fc-HA plasmids were purchased from Sino Biology Inc. (Beijing, China). The pCMV2-SLPI-HA plasmid contains human SLPI cDNA together with the hygromycin resistant gene for protein expression and selection in the eukaryotic system.

Recombinant human SLPI (rhSLPI) was purchased from Sino Biology Inc. (Beijing, China), and Dulbecco's modified Eagle's medium (DMEM), fetal bovine serum and trypsin-EDTA (Gibco BRL; Life Technologies Inc. New York,
USA). Other reagents includedlactatedehydrogenase(LDH) liquid-UV test was from Human (Wiesbaden, Germany), 3-(4,5-dimethyl-2-thiazol)-2,5-diphenyl-2Htetrazolium bromide (MTT) was obtained from Ameresco (Solon, Ohio, USA), and total p38, phosphorylated-p38, total Akt, and phosphorylated-Akt were from Santa Cruz Biotech (California, USA). Other chemicals were obtained from Sigma.

\section{Cell culture}

Rat cardiac myoblast cell line, H9c2 cell line (ATCC number CRL-1446), was maintained in Dulbacco's modified Eagle's medium (DMEM) supplemented with 10\% heat-inactivated fetal bovine serum, $100 \mathrm{unit} / \mathrm{ml}$ of penicillin and $100 \mu \mathrm{g} /$ $\mathrm{ml}$ streptomycin. The $\mathrm{H} 9 \mathrm{c} 2$ cells were maintained at $37^{\circ} \mathrm{C}$, $5 \% \mathrm{CO}_{2}+95 \% \mathrm{O}_{2}$ until they reached $80 \%$ confluence.

\section{Establishment of stable cardiac cell line overexpressing rhSLPI}

The H9c2 cells were seeded at a density of $1 \times 10^{5}$ cells/ well in a 6-well plate in DMEM complete medium until the cell density reached to $80 \%$ confluence. The cells were transfected with $\mathrm{pCMV}_{2}$-SLPI-HA plasmid or $\mathrm{pCMV}_{2}-\mathrm{Fc}-\mathrm{HA}$ plasmid (mock transfection) using an $\mathrm{H} 9 \mathrm{c} 2$ transfection kit purchased from Altogen Biosystems ${ }^{\circledR}$. After transfection, the cells were incubated in DMEM complete medium for an additional $48 \mathrm{~h}$, and then transferred to DMEM complete medium containing $500 \mathrm{ug} / \mathrm{ml}$ hygromycin B (Invitrogen, Carlsbad, CA, US). Continuous drug selection was carried out on expanded transfected clonal cells that were derived from a single cell, until the stable cell line was established. The level of rhSLPI expression was monitored with a human SLPI ELISA kit (R\&D Systems). The stable cell lines were cultured for at least three passages before performing the experiment.

\section{Determination of the growth curve and population doubling time}

The H9c2 cells at a concentration of $5 \times 10^{5}$ cells $/ \mathrm{ml}$ containing pCMV-SLPI-HA and pCMV-Fc-HA plasmid were cultured on a 24-well plate with DMEM complete medium containing $500 \mu \mathrm{g} / \mathrm{ml}$ hygromycin $\mathrm{B}$ at $37{ }^{\circ} \mathrm{C}, 5 \% \mathrm{CO}_{2}$, and $95 \% \mathrm{O}_{2}$ for 7 days. The MTT cell proliferation assay was performed and the data was used to generate the growth curve. All groups were harvested and counted every day 
for 7 days. Cell numbers were used to calculate the PDT by the following formula.

$$
T d=(t 2-t 1) \times \frac{\log (q 2)}{\log \left(\frac{q 2}{q 1}\right)}
$$

$\mathrm{q} 1=$ Quantity of the cells at start time. $(1 \mathrm{unit} / \mathrm{h})$

$\mathrm{q} 2=$ Quantity of the cells at the end. (1 unit/h)

$\mathrm{t} 1=$ starting time $(\mathrm{h})$

$\mathrm{t} 2=$ ending time $(\mathrm{h})$

\section{Determination of cell morphology}

Three cell types, including the parental H9c2 cells, the mock transfected cells, and the overexpressing rhSLPI H9c2 cells, at a concentration of $1 \times 10^{5}$ were grown on cell culture slides (SPL Life Sciences, Korea) and cultured in complete medium at $37{ }^{\circ} \mathrm{C}, 5 \% \mathrm{CO}_{2}$ at sub-confluent densities. The cells on cell culture slides were washed with PBS then fixed with a fixative agent ( $2 \%$ formaldehyde, $0.05 \%$ glutaraldehyde) at room temperature for $30 \mathrm{~min}$. The cells were permeabilized with $0.5 \%$ Triton-X 100 in PBS for $20 \mathrm{~min}$ and then, stained with $50 \mu \mathrm{g} / \mathrm{ml}$ of FITCconjugated phalloidin (Sigma Co, St. Louis, USA) for 40 min in a dark moist box. Subsequently, the cell culture slides were washed with PBS before nuclear staining with $0.01 \mu \mathrm{g} / \mathrm{ml}$ DAPI (Sigma Co, St. Louis, USA) for 20 min. The cell culture slides were mounted by adding 20 $\mu \mathrm{l}$ of $50 \%$ glycerol on a glass slide and the edges sealed with nail varnish. These samples were kept in a dark box until being visualised in a fluoroscopic process, when the actin cytoskeleton was visualized under fluorescence microscopy (Carl Zeiss, Jena GmbH, Germany).

\section{Determination of protease enzyme inhibitory activity of rhSLPI secreted from the $\mathrm{H} 9 \mathrm{c} 2$ cells overexpressing rhSLPI}

A $1 \times 10^{5}$ cells/ml sample containing pCMV-SLPI-HA, mock transfection, were cultured in a 6-well plate with DMEM complete medium supplemented with $500 \mu \mathrm{g} / \mathrm{ml}$ hygromycin $\mathrm{B}$ at $37^{\circ} \mathrm{C}, 5 \% \mathrm{CO}_{2}$, and $95 \% \mathrm{O}_{2}$ for 2 days. The culture medium was then collected and concentrated 40fold using an Amicon Ultra filter device (Merck, Germany). The protease inhibitory activity of the rhSLPI concentrated protein was determined using a Pierce ${ }^{\mathrm{TM}}$ Colorimetric Protease Assay Kit (Thermo Fisher Scientific Inc., United Kingdom). Briefly, $100 \mu \mathrm{l}$ of succinylated casein solution was added to microplate wells. Consequently, $100 \mu \mathrm{l}$ of assay buffer was applied to the microplate wells followed by $50 \mu \mathrm{l}$ of $125 \mu \mathrm{g} / \mathrm{ml}$ trypsin or $50 \mu \mathrm{l}$ of sample mixture (containing $5 \mu \mathrm{l}, 15 \mu \mathrm{l}$, and $30 \mu \mathrm{l}$ concentrated culture medium and trypsin; the final concentration of trypsin in the mixture was $125 \mu \mathrm{g} / \mathrm{ml}$ ). The mixed solution was incubated for $20 \mathrm{~min}$ at room temperature, and then TNBSA working solution was applied to each well. Then, the microplate was incubated for $20 \mathrm{~min}$ at room temperature. The color of the solution was determined by the spectrophotometric method at $\lambda 450 \mathrm{~nm}$. The activity of the rhSLPI was in inverse proportion to the color intensity.

\section{Simulated ischemia (sl)}

Simulated ischemia (sI) was induced by incubating H9c2 cells with specified modified Krebs-Henseleit buffer (137 $\mathrm{mM} \mathrm{NaCl}, 3.8 \mathrm{mM} \mathrm{KCl}, 0.49 \mathrm{mM} \mathrm{MgCl}_{2}, 0.9 \mathrm{mM} \mathrm{CaCl}_{2}$, and 4.0 mM HEPES) supplemented with $20 \mathrm{mM}$ 2-deoxyglucose, 20 $\mathrm{mM}$ sodium lactate, and $1 \mathrm{mM}$ sodium dithionite at $\mathrm{pH}$ 6.5. Control buffer was composed of Krebs-Henseleit buffer supplemented with $20 \mathrm{mM}$ D-glucose and $1 \mathrm{mM}$ sodium pyruvate. Cells were subjected to sI at $37^{\circ} \mathrm{C}, 5 \% \mathrm{CO}_{2}$ for 40 min before changing to complete medium for reperfusion and incubated at $37^{\circ} \mathrm{C}, 5 \% \mathrm{CO}_{2}$ for $24 \mathrm{~h}$.

\section{Measurement of cell viability}

H9c2cellswerecultured orexposedinanotherexperimental procedure. After the culture media was removed, $0.5 \mathrm{mg} /$ $\mathrm{ml}$ MTT reagent was added and incubated for $2 \mathrm{~h}$ at $37^{\circ} \mathrm{C}$. After incubation, the excess MTT reagent was discarded and DMSO was added for solubilizing the formazan dye. The formazan dye was collected and the optical density (OD) was determined by a spectrophotometer at $\lambda 490 \mathrm{~nm}$ using DMSO as a blank. The relative percentage of cell viability was compared to the control group.

\section{Measurements of cellular injury}

The LDH activity assay kit used in this study is the modified method based on the recommendations of the Scandinavian Committee on Enzymes (LDHSCE mod.). The kit was purchased from HUMAN (Wiesbaden, Germany). Ten microliters of culture medium was mixed with 1000 $\mu \mathrm{l}$ reaction buffer and incubated at $37^{\circ} \mathrm{C}$ for $5 \mathrm{~min}$. Then, $250 \mu \mathrm{l}$ of substrate reagent was added. The solution was 
mixed and the absorbance read after $1 \mathrm{~min}$ at $\Lambda 340 \mathrm{~nm}$. The mean absorbance change per minute $(\Delta \mathrm{A} / \mathrm{min})$ was used to calculate LDH activity by the following formula; LDH activity $(\mathrm{U} / \mathrm{I})=\Delta \mathrm{A} / \mathrm{min} \mathrm{X} 20,000$

\section{Determination of cellular reactive oxygen species (ROS)}

A $1 \times 10^{5}$ cells/ml of $\mathrm{H} 9 \mathrm{c} 2$ cells was cultured in a 96well black plate with DMEM complete medium at $37{ }^{\circ} \mathrm{C}$, $5 \% \mathrm{CO}_{2}$, and 95\% $\mathrm{O}_{2}$ until $80 \%$ confluence. The culture media was removed and the cells washed once with PBS before incubating with complete media containing 250 $\mu \mathrm{M}$ carboxy-H2DCFDA in a dark room for $30 \mathrm{~min}$ at 37 ${ }^{\circ} \mathrm{C}$. Later, the medium containing carboxy-H2DCFDA was discharged and the cells were washed once with PBS. For the rhSLPI treatment experiment, $200 \mu \mathrm{l}$ of DMEMcompleted medium containing various concentrations of rhSLPI was added and incubated for $1 \mathrm{~h}$ at $37^{\circ} \mathrm{C}$. Then, 250 $\mu \mathrm{M} \mathrm{H}_{2} \mathrm{O}_{2}$ was applied to the cells and incubated for $30 \mathrm{~min}$ at $37^{\circ} \mathrm{C}$. The ROS activity was determined by measuring the fluorescence intensity with an EnSpire Multimode Plate Readers (PerkinElmer, Massachusetts, USA). The filter suitable for detecting the signal gave an excitation wavelength of $\lambda 498 \mathrm{~nm}$ and emission wavelength of $\lambda 522$ nm.

\section{Measurement of p38 MAPK and Akt activa- tion by Western blot analysis}

H9c2 cells were extracted at the end of the study protocols. The supernatants were collected and an equal volume of 2X SDS-PAGE sample buffer, containing 10\% (v/v) $\beta$-mercaptoethanol and bromophenol blue dye, was added. The samples were boiled for $10 \mathrm{~min}$ and stored at $-80{ }^{\circ} \mathrm{C}$ before analysis. The extract proteins were separated on $12 \%$ SDS-polyacrylamide gels; transferred to polyvinylidenedifluoride (PVDF) membranes, which were blocked for $1 \mathrm{~h}$ with 5\% nonfat milk $+1 \%$ bovine serum albumin in Tris-buffered saline ( $\mathrm{pH}$ 7.4) containing $0.1 \%$ Triton X-100; and probed overnight at $4{ }^{\circ} \mathrm{C}$ with the appropriate primary antibody as follows: total p38 (1:1000), diphospho-p38 (1:1000), total Akt (1:1000), and phospho-Akt(1:1000). After washing and exposure for $1 \mathrm{~h}$ at room temperature to horseradish peroxidase-conjugated secondary antibody, antibody-antigen complexes were visualized by enhanced chemiluminescence. Bands corresponding to the detected protein of interest were detected by chemiluminescence gel documentation.
Band densities were quantified and compared providing information on relative abundance of the protein of interest.

\section{Statistical analysis}

All values were expressed as Mean \pm S.E.M. All comparisons were assessed for significance using ANOVA, followed when appropriate by the Tukey-Kramer test. The statistical tests were performed using commercially available software (Lab chart Prism version 5). A p-value less than 0.05 was considered as statistically significant.

\section{Results}

\section{Establishment of stable cardiac cell Line expressing rhSLPI}

H9c2 cells were transfected with pCMV2-SLPI-HA and pCMV2-FC-HA (mock) plasmids using the Altogen transfection reagent kit. The successfully transfected cells were selected by limiting dilution in the presence of 500 $\mu \mathrm{g} / \mathrm{ml}$ of hygromycin B. The stable cell lines overexpressing rhSLPI were generated from a single colony of transfected cells until the appropriate amount for the experiment was reached. The expression of rhSLPI proteins was measured from the whole cell lysate and culture medium from all groups, including the parental H9c2 cells, the mock transfected cells, and the pCMV2-SLPI-HA transfected cells, by ELISA. The results showed that the expression of rhSLPI in the stable cell line overexpressing rhSLPI was significantly higher than that of the parental H9c2 cells and mock transfected cells in both the whole cell lysate $(93.93 \pm 18.99 \mathrm{pg} / \mathrm{ml}, 44.62 \pm 7.44 \mathrm{pg} / \mathrm{ml}$ and $46.58 \pm 9.17$ $\mathrm{pg} / \mathrm{ml}, p<0.05)$ and the culture medium $(547.26 \pm 27.11$ $\mathrm{pg} / \mathrm{ml}, 39.98 \pm 7.02 \mathrm{pg} / \mathrm{ml}$ and $41.35 \pm 4.47 \mathrm{pg} / \mathrm{ml}, p<0.05)$ (Figure 1A).

After establishing the stable cardiac cell line overexpressing rhSLPI, the alteration in the biological properties of the stable cells, including growth curve, population doubling time (PDT), and cell morphology, were measured and compared to the parental H9c2 cells and mock transfection cells.

The growth curve of the parental H9c2 cells, mock transfection cells, and the stable cell lines overexpressing rhSLPI, were not different (Figure 1B). The PDT in those three cell groups including parental H9c2 cells (49.09 \pm $2.96 \mathrm{~h})$, mock transfection cells (49.12 $\pm 1.191 \mathrm{~h})$, and the 

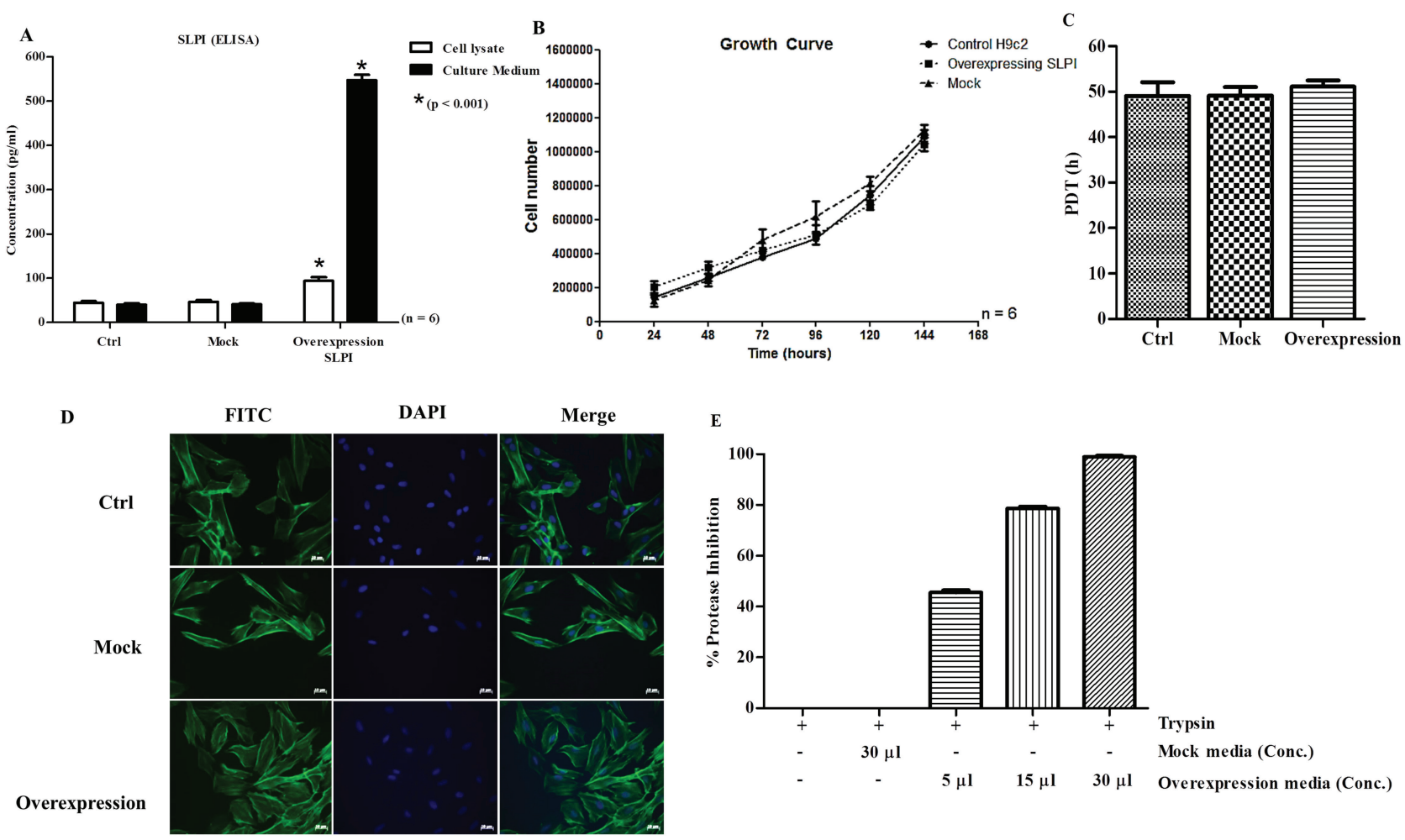

Figure 1: The biological properties of the stable $\mathrm{H} 9 \mathrm{c} 2$ cell lines overexpressing rhSLPI. $\mathrm{H} 9 \mathrm{c} 2$ cells were transfected with $\mathrm{pCMV} \mathrm{C}_{2}-\mathrm{Fc}-\mathrm{HA}$ and $\mathrm{pCMV}_{2}$-SLPI-HA plasmids and the level of rhSLPI expression, growth curve, PDT, cell morphology, and protease inhibitory activity, were determined. After transfection, (A) the protein expression of rhSLPI in cell lysate and culture media were monitored using a human SLPI ELISA kit; $(B, C)$ the parental H9c2 cells, the mock transfected cells, and the stable H9c2 cell lines overexpressing rhSLPI, were counted every day for 7 days to determine the growth curve and PDT; (D) the cell morphology was determined by staining with FITC-conjugated phalloidin and DAPI and visualized under fluorescence microscopy; (E) $5 \mu \mathrm{l}, 15 \mu \mathrm{l}$, and $30 \mu \mathrm{l}$ concentrated rhSLPI protein and $30 \mu \mathrm{l}$ concentrated protein from the mock transfection were incubated with $125 \mu \mathrm{g} / \mathrm{ml}$ trypsin and the absorbance was then measured spectrophotometrically at $\lambda 450 \mathrm{~nm}$.

stable cell lines overexpressing rhSLPI $(51.13 \pm 1.36 \mathrm{~h})$ were not statistically different (Figure 1C). The cell morphology of all three cell types was not different in terms of size, shape, and cytoskeleton organization (Figure 1D).

\section{The rhSLPI secreted from the stable H9c2 cells overexpressing rhSLPI manifested serine protease inhibitory activity}

We also determined the serine protease activity of rhSLPI secreted from the stable cell lines overexpressing rhSLPI. The results showed that the activity of trypsin was significantly decreased when the concentrated culture media of the stable cell lines overexpressing rhSLPI was applied to the reaction, as compared to the $125 \mu \mathrm{g} /$ $\mathrm{ml}$ standard trypsin reaction (Figure $1 \mathrm{E}$ ). Moreover, the results indicated that $5 \mu \mathrm{l}, 15 \mu \mathrm{l}$, and $30 \mu \mathrm{l}$ concentrated culture media of the stable cell lines overexpressing rhSLPI inhibited trypsin activity at $45.56 \%, 78.60 \%$, and $98.83 \%$, respectively, (Figure 1E) in a dose-dependent manner. However, the concentrated culture medium of the mock transfection cells did not inhibit the trypsin activity.

\section{Overexpression of rhSLPI increased cell viability of $\mathrm{H} 9 \mathrm{c} 2$ cells against simulated ischemia/reperfusion}

After the stable cardiac cell lines overexpressing rhSLPI were successfully generated, the effects of overexpressing rhSLPI to reduce ischemia-induced cardiac cell death and cell injury in H9c2 cells were investigated. Three cells groups, including the parental $\mathrm{H} 9 \mathrm{c} 2$ cell, the mock transfected cell and the stable cardiac cell lines overexpressing rhSLPI, were exposed to $40 \mathrm{~min}$ simulated ischemia (sI) buffer followed by $24 \mathrm{~h}$ of reperfusion. After that, relative cell viability and cell injury were measured by 


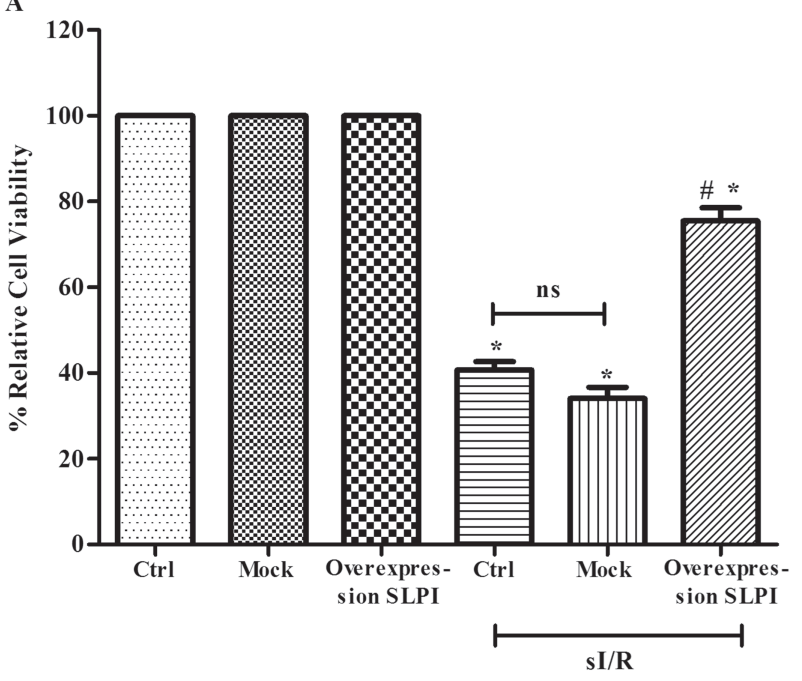

B

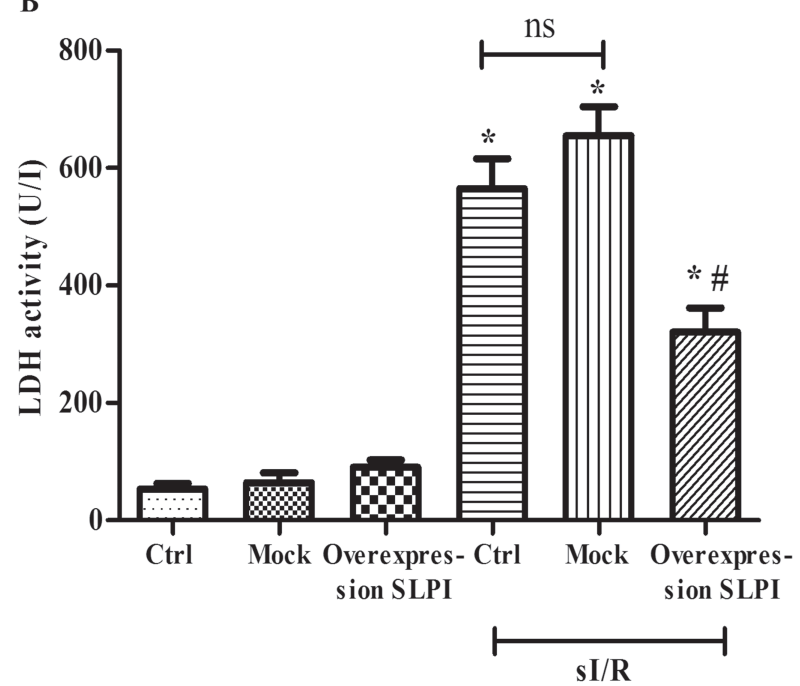

Figure 2: Determination of the effects of overexpression of rhSLPI in H9c2 cells subjected to sl/R. Three cells groups, including the parental H9c2 cells (Ctrl), the mock transfected cells, and the stable H9c2 cell lines overexpressing rhSLPI, were subjected to 40 min simulated ischemia (sl) followed by $24 \mathrm{~h}$ of reperfusion. (A) Cell viability and (B) cell injury were measured by MTT cell survival assay and released LDH activity assay. Each bar graph represents the means \pm S.E.M for each of the three experiments. ${ }^{*} p<0.05$ vs control group (ANOVA), \# $p<$ 0.05 vs among treated groups (ANOVA).

MTT cell survival assay and released LDH activity assay. The results showed that the relative percentage of cell viability of the stable cardiac cell lines overexpressing rhSLPI $(77 \pm 7.45 \%)$ was significantly higher than that of the parental H9c2 cells $(49 \pm 5.26 \%)$ and mock transfected cells (34 $\pm 6.98 \%$ ) (Figure $2 \mathrm{~A})$. Moreover, the stable cardiac cell lines overexpressing rhSLPI significantly reduced released LDH activity during sI/R challenging when compared to parental cells and mock transfection cells $(320 \pm 25.82 \mathrm{U} / \mathrm{I}, 565 \pm 24.22 \mathrm{U} / \mathrm{I}$, and $655 \pm 98.49 \mathrm{U} / \mathrm{I}$, $p<0.05$ ) (Figure 2B).

\section{Overexpression of rhSLPI decreases intracellular ROS level in $\mathrm{H} 9 \mathrm{c} 2$ cells}

Besides acting as an anti-protease, SLPI also has other important biological properties, in particular increasing glutathione levels in the lung [15]. Therefore, the alterations of cellular ROS level in the stable cardiac cell lines overexpressing rhSLPI after sI/R injury was investigated. Three cell types including the parental H9c2 cells, mock transfected cells, and the stable cardiac cell lines overexpressing rhSLPI, were exposed to carboxyH2DCFDA followed by $\mathrm{H}_{2} \mathrm{O}_{2}$ challenging. The results showed that $\mathrm{H}_{2} \mathrm{O}_{2}$ challenging in the parental $\mathrm{H} 9 \mathrm{c} 2$ cells (Control cells) and mock transfected cells, significantly increased the production of cellular ROS when compared

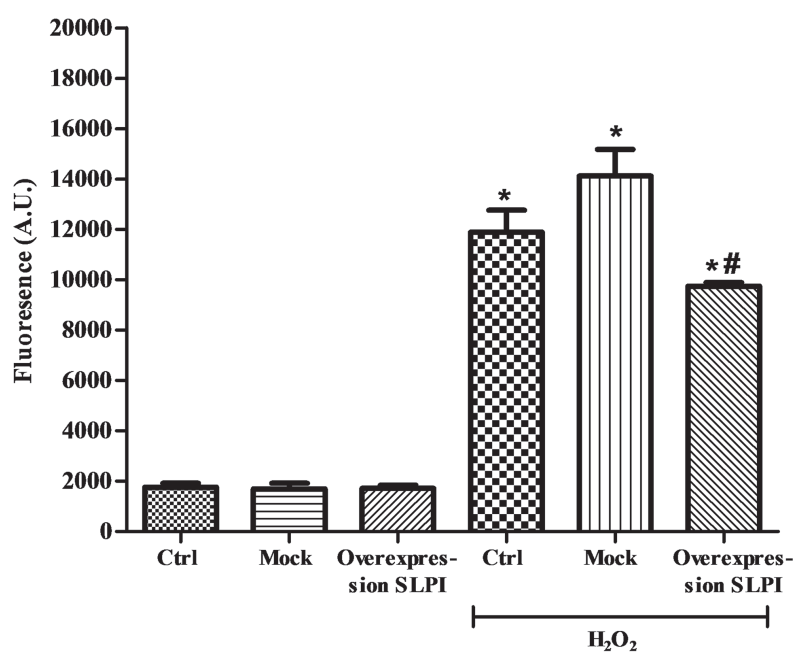

Figure 3: Determination of cellular ROS level of the stable H9c2 cell lines overexpressing rhSLPI challenging with $\mathrm{H}_{2} \mathrm{O}_{2}$. $\mathrm{H} 9 \mathrm{c} 2$ cells were incubated with carboxy-H2DCFDA. After incubation, $\mathrm{H}_{2} \mathrm{O}_{2}$ was applied to each cell group and the cellular ROS level was determined spectrophotometrically. Each bar graph represents the means \pm S.E.M for each of the three experiments. ${ }^{*} p<0.05$ vs control cell (ANOVA) and $\# \mathrm{p}<0.05$ among $\mathrm{H}_{2} \mathrm{O}_{2}$ treated group (ANOVA).

to the basal ROS level in parental H9c2 cells and mock transfected cells (H9c2 cells $1767 \pm 275.1$ A.U. vs H9c2 cells $+\mathrm{H}_{2} \mathrm{O}_{2} 11,887 \pm 1526$ A.U., $p<0.05$ ), (Mock cells 1701 \pm 373.8 A.U. vs Mock cells $+\mathrm{H}_{2} \mathrm{O}_{2} 14,112 \pm 1840$, A.U., $p$ $<0.05$ ) (Figure 3). Interestingly, the cellular ROS level in 

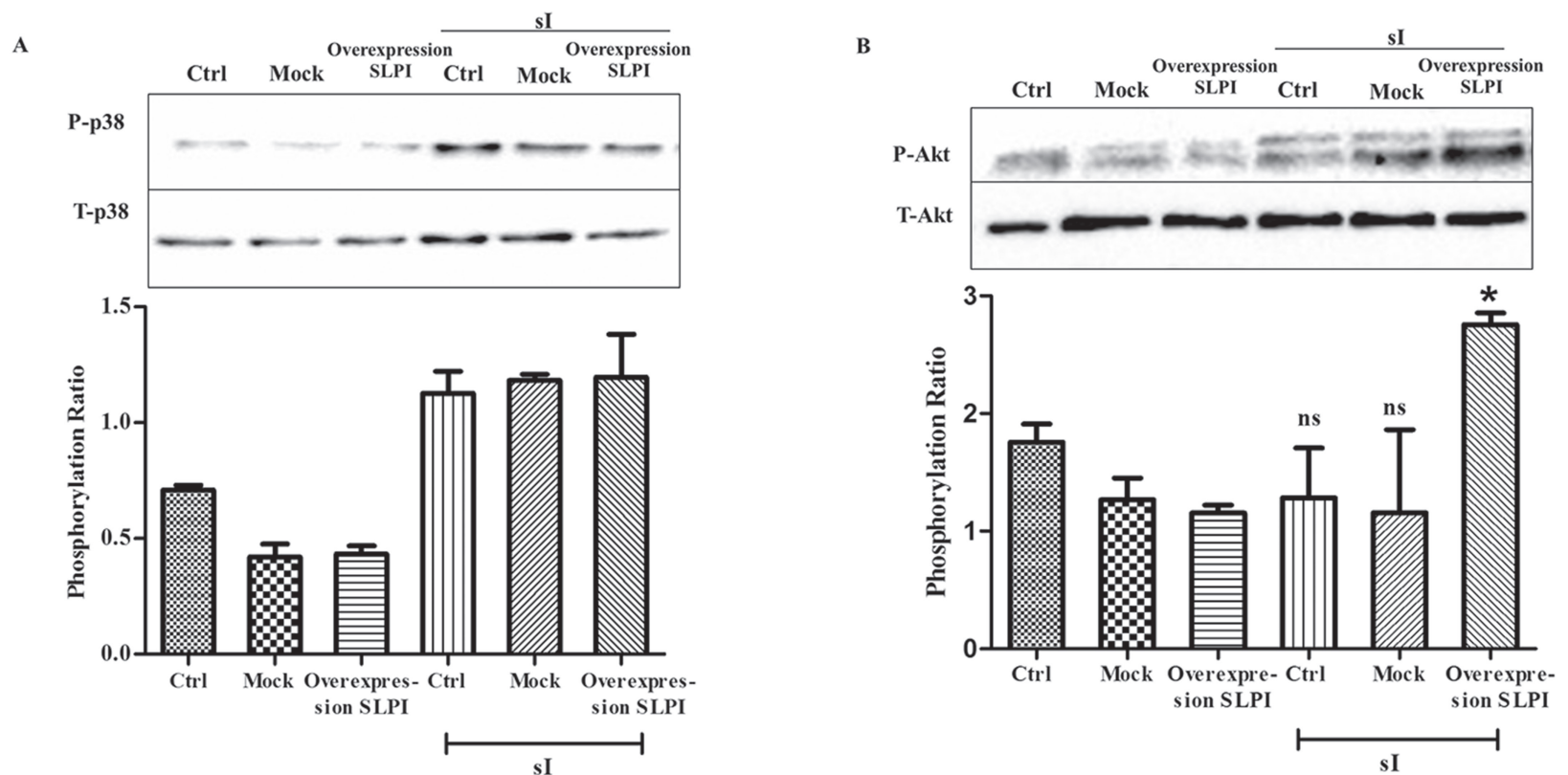

Figure 4: Effects of the overexpression of rhSLPI in H9c2 cells on p38 MAPK and Akt activation during sl. The parental H9c2 cells, the mock transfected cell, and the stable H9c2 cell lines overexpressing rhSLPI, were subjected to sl. The cells were then harvested, and p38 MAPK (p-P38) and Akt (p-Akt) activation were assessed by Western Blot. (A) p38 MAPK activation; (B) Akt activation. Each bar graph represents fold phosphorylation of $\mathrm{p} 38$ MAPK and Akt for three experiments. * $p<0.05$ vs control of each group (ANOVA).

the stable cardiac cell lines overexpressing rhSLPI (9751 \pm 236.4) was significantly decreased during $\mathrm{H}_{2} \mathrm{O}_{2}$ challenging when compared to the parental H9c2 cells $(11,887 \pm 1526)$ and the mock transfected cells $(14,112 \pm 1840, p<0.05)$ (Figure 3).

\section{Overexpression of rhSLPI increased Akt phosphorylation but did not attenuate $\mathrm{p} 38$ MAPK}

Myocardial ischemia/reperfusion injury (I/R) is a potent stimulant of p38 MAPK activation, which leads to myocardial cell death and cell injury [16-20]. Since the overexpression of rhSLPI in H9c2 cells could reduce cell death and cell injury in $\mathrm{sI} / \mathrm{R}$, we hypothesized that the decrease of cell death and cell injury by overexpression of rhSLPI in H9c2 cells could attenuate p38 MAPK activation. The cells were exposed to $10 \mathrm{~min}$ of sI, and the cellular protein was then collected and the p38 MAPK activation was determined by Western blot analysis. The results showed that simulated ischemia could induce p38 MAPK phosphorylation (Figure 4A).

Protein kinase B (PKB), also known as Akt, is a serine/threonine protein kinase that plays a role in the survival pathway of cells [21-24]. Activation of Aktdependent signaling could attenuate cardiomyocyte apoptosis and reduce myocardial $\mathrm{I} / \mathrm{R}$ injury [21-24]. Therefore, we hypothesized that the overexpression of rhSLPI could activate the Akt phosphorylation during sI/R stimulation. The results showed that Akt phosphorylation was significantly higher in the stable cardiac cell lines overexpressing rhSLPI when compared to the parental H9c2 cells and the mock transfection cells (Figure 4B).

\section{Only pretreatment of rhSLPI prior sI/R improves cardiac cell death and cell injury during simulated ischemia/reperfusion}

H9c2 cells were cultured with $0 \mathrm{ng} / \mathrm{ml}, 1 \mathrm{ng} / \mathrm{ml}, 100 \mathrm{ng} /$ $\mathrm{ml}, 1 \mu \mathrm{g} / \mathrm{ml}, 10 \mu \mathrm{g} / \mathrm{ml}$ and $20 \mu \mathrm{g} / \mathrm{ml}$ of rhSLPI. This was performed in three different periods including treating the rhSLPI for $24 \mathrm{~h}$ prior to sI, at the onset of sI, and at the onset of reperfusion. The simulated ischemia was performed for $40 \mathrm{~min}$ followed by $24 \mathrm{~h}$ reperfusion (sI/R). After reperfusion, the culture medium was collected for measuring the released LDH enzyme activity and relative cell viability was then determined by MTT assay. The results showed that pretreatment with rhSLPI at $1 \mu \mathrm{g} / \mathrm{ml}$ and $10 \mu \mathrm{g} / \mathrm{ml}$ prior to sI/R significantly reduced simulated ischemia-induced cell death when compared to the untreated group $(73.5 \pm 2.07 \%, 73.3 \pm 2.80 \%$, vs $49.50 \pm$ $5.08 \%$ ) (Figure $5 \mathrm{~A})$ and these concentrations $(1 \mu \mathrm{g} / \mathrm{ml}$ and 
A

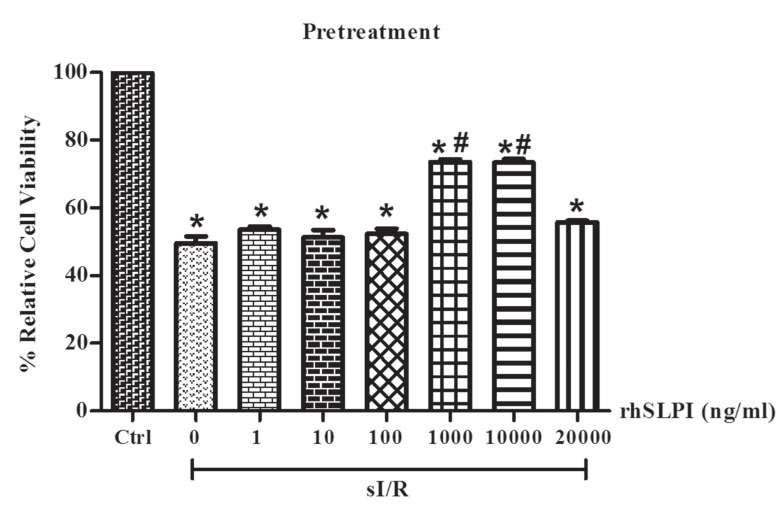

C

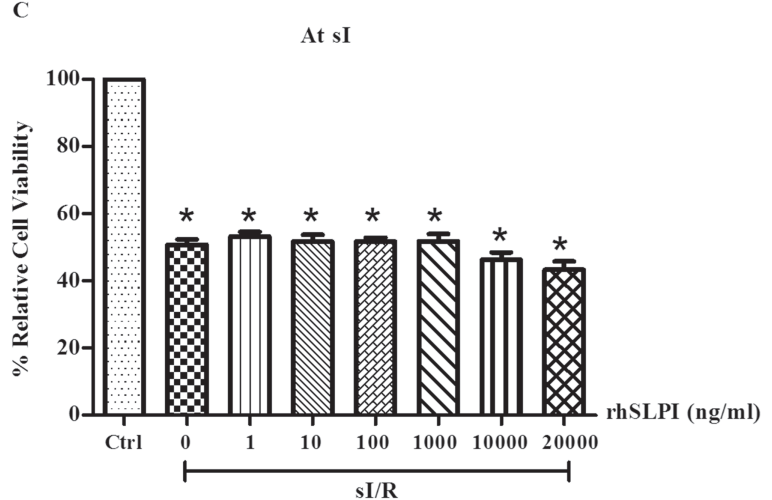

$\mathbf{E}$

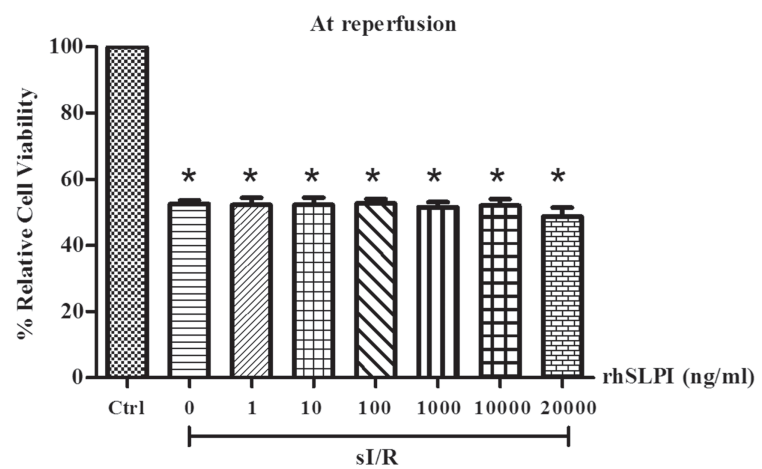

B

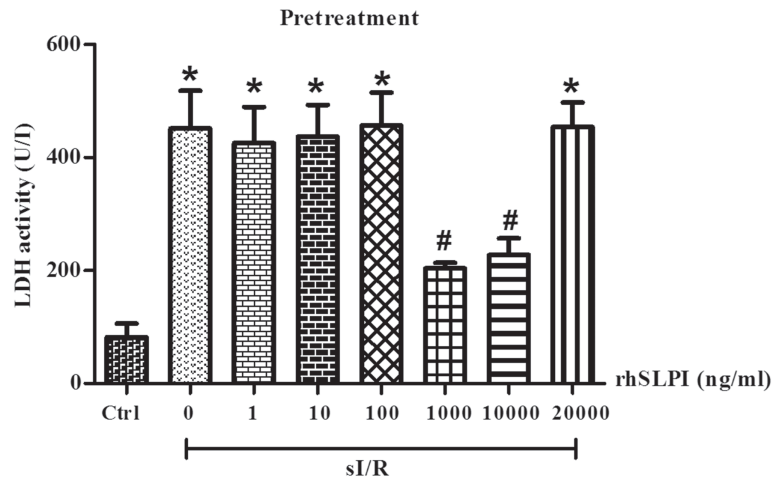

D
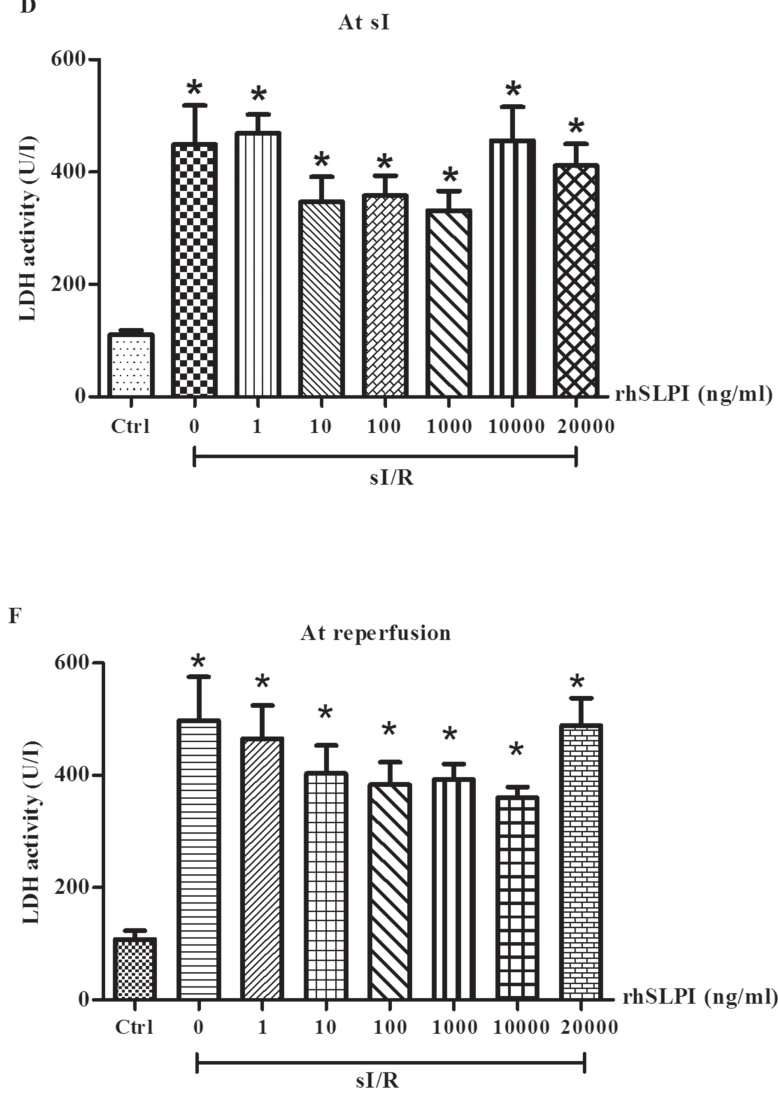

Figure 5: Determination of the effects of recombinant human SLPI (rhSLPI) on H9c2 cells subjected sI/R. The H9c2 cells were divided into three groups, including treatment of rhSLPI $24 \mathrm{~h}$ prior to ischemia or pre-treatment, rhSLPI treatment at the onset of ischemia, and rhSLPI treatment at the onset of reperfusion. After treatment, all groups were subjected to $40 \mathrm{~min}$ sl followed by $24 \mathrm{~h}$ reperfusion. The percentage of cell viability $(5 \mathrm{~A}, 5 \mathrm{C}, 5 \mathrm{E})$ and released $\mathrm{LDH}$ activity of all groups $(5 \mathrm{~B}, 5 \mathrm{D}, 5 \mathrm{~F})$ were determined. Each bar graph represents means $\pm \mathrm{S} . \mathrm{E} . \mathrm{M}$ for each of the six experiments. ${ }^{*} p<0.05$ vs control group (ANOVA), $\# p<0.05$ vs sl (ANOVA).

$10 \mu \mathrm{g} / \mathrm{ml}$ ) also significantly decreased the released LDH activity when compared to the untreated group (204 \pm $21.90 \mathrm{U} / \mathrm{I}, 227.5 \pm 84.81 \mathrm{U} / \mathrm{I}$, and $451.4 \pm 66.74 \mathrm{U} / \mathrm{I}$ ) (Figure 5B). In addition, treatment with rhSLPI at the onset of ischemia (Figure 5C), as well as at the onset of reperfusion
(Figure 5E), did not increase cell viability of cardiac cells after sI/R. Furthermore, the release of the LDH enzyme was related to cell viability in that the LDH activity was not significantly reduced when treated with rhSLPI at the onset of ischemia and reperfusion (Figure 5D, 5F). The 

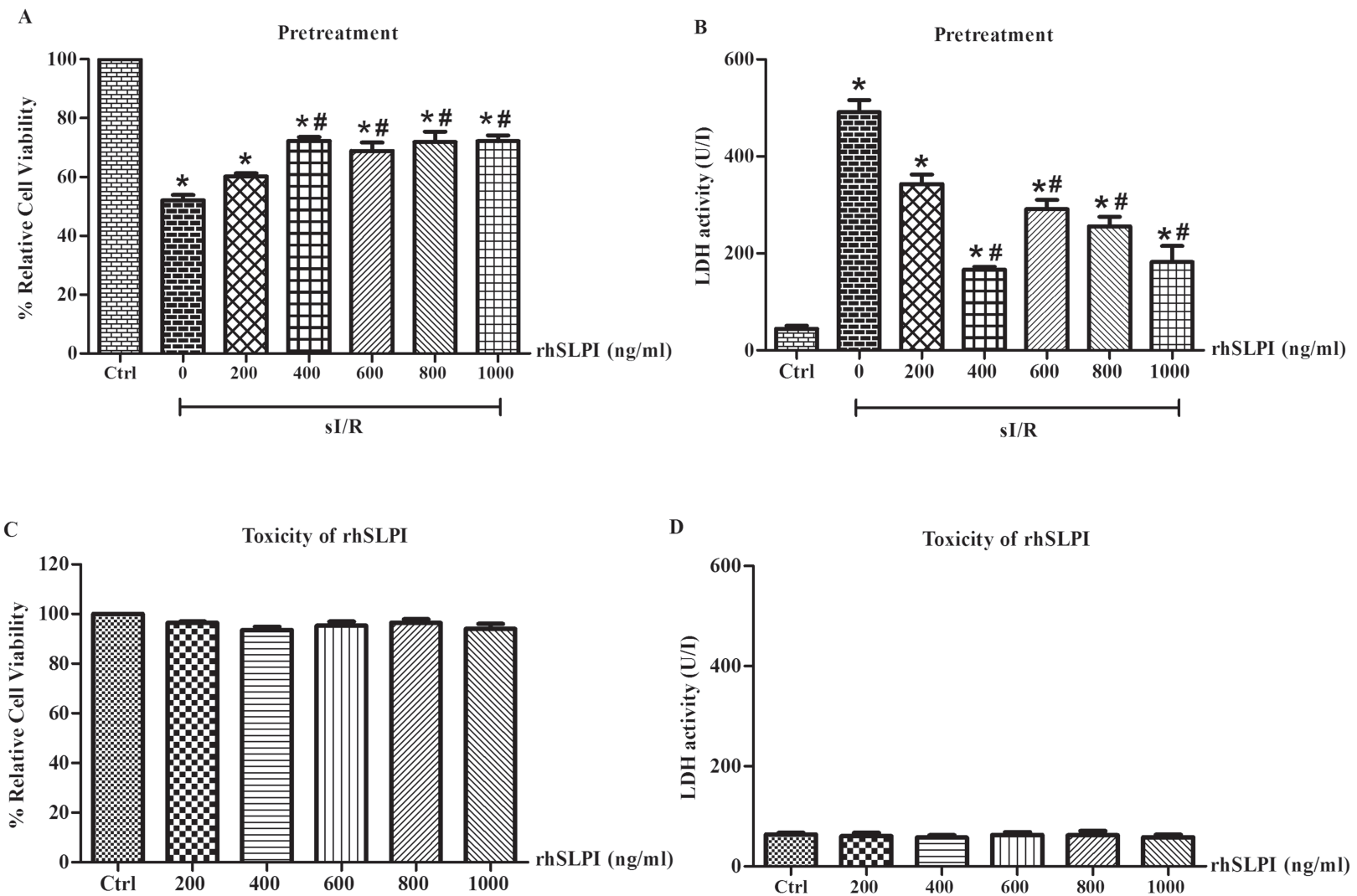

Figure 6: Identification of the maximum rhSLPI concentration required to provide cardio-protection on H9c2 cells subjected to sl/R. H9c2 cells were treated with rhSLPI at $200 \mathrm{ng} / \mathrm{ml}, 400 \mathrm{ng} / \mathrm{ml}, 600 \mathrm{ng} / \mathrm{ml}, 800 \mathrm{ng} / \mathrm{ml}$ and $1000 \mathrm{ng} / \mathrm{ml}$ for $24 \mathrm{~h}$ prior to simulated ischemia followed by $24 \mathrm{~h}$ reperfusion. (6A) shows the percentage of cell viability of $\mathrm{H} 9 \mathrm{c} 2$ cells treated with various concentrations of rhSLPI; (6B) illustrating the release of LDH activity after the cells were treated with various concentrations of rhSLPI; (6C) The percentage of cell viability and (6D) release of LDH activity after cells incubated with various concentrations of rhSLPI without sI/R are shown. Each bar graph represents means \pm S.E.M for each of the six experiments. ${ }^{*} p<0.05$ vs control group (ANOVA), $\# p<0.05$ vs sl (ANOVA).

minimum concentration which gave cardio-protection in H9c2 cells was $1 \mu \mathrm{g} / \mathrm{ml}$.

\section{Pretreatment of rhSLPI, $400 \mathrm{ng} / \mathrm{ml}-1000$ $\mathrm{ng} / \mathrm{ml}$, protected cardiac cell lines against ischemia/reperfusion injury}

The minimum concentration of rhSLPI on cardiac cell lines subjected to sI/R was $1 \mu \mathrm{g} / \mathrm{ml}$. We attempted to identify the maximum rhSLPI concentration required to give cardioprotection on H9c2 cells. We cultured H9c2 cells in $0 \mathrm{ng} /$ $\mathrm{ml}, 200 \mathrm{ng} / \mathrm{ml}, 400 \mathrm{ng} / \mathrm{ml}, 600 \mathrm{ng} / \mathrm{ml}, 800 \mathrm{ng} / \mathrm{ml}$, and $1 \mu \mathrm{g} / \mathrm{ml}$ concentrations of rhSLPI $24 \mathrm{~h}$ prior to sI. After treatment, all groups of the cells were subjected to sI for $40 \mathrm{~min}$ followed by $24 \mathrm{~h}$ of reperfusion. After reperfusion, the culture medium was collected for assessing the released LDH enzyme activity and relative cell viability was determined by MTT assay.
The results showed that after $24 \mathrm{~h}$ of reperfusion, the relative percentage of cell viability of the SLPI treated group gradually increased when compared to the untreated group. The rhSLPI at concentrations of $400-1000 \mathrm{ng} / \mathrm{ml}$ significantly increased the cell viability of the cardiac cell lines exposed to $\mathrm{SI} / \mathrm{R}$ injury when compared to the untreated group $(72.20 \pm 4.04 \%, 68.84 \pm 8.47 \%, 71.89 \pm$ $10.55 \%$, vs $72.17 \pm 5.84 \%$; $<$ < 0.05) (Figure 6A). Moreover, treatment with rhSLPI $24 \mathrm{~h}$ prior to sI/R significantly reduced released LDH activity as well, especially at 400 $\mathrm{ng} / \mathrm{ml}(166.7 \pm 17.32 \mathrm{U} / \mathrm{I})$, when compared to the untreated group $(491.4 \pm 25.02 \mathrm{U} / \mathrm{I})$ (Figure 6B). We then investigated the toxicity of rhSLPI by culturing the H9c2 cells with 0 $\mathrm{ng} / \mathrm{ml}, 200 \mathrm{ng} / \mathrm{ml}, 400 \mathrm{ng} / \mathrm{ml}, 600 \mathrm{ng} / \mathrm{ml}, 800 \mathrm{ng} / \mathrm{ml}$, and $1000 \mathrm{ng} / \mathrm{ml}$ of rhSLPI for $24 \mathrm{~h}$, and cell death and cell injury were measured. The results showed that treatment with rhSLPI did not reduce cell viability, and did not increase released LDH activity (Figure 6C, 6D). 
A

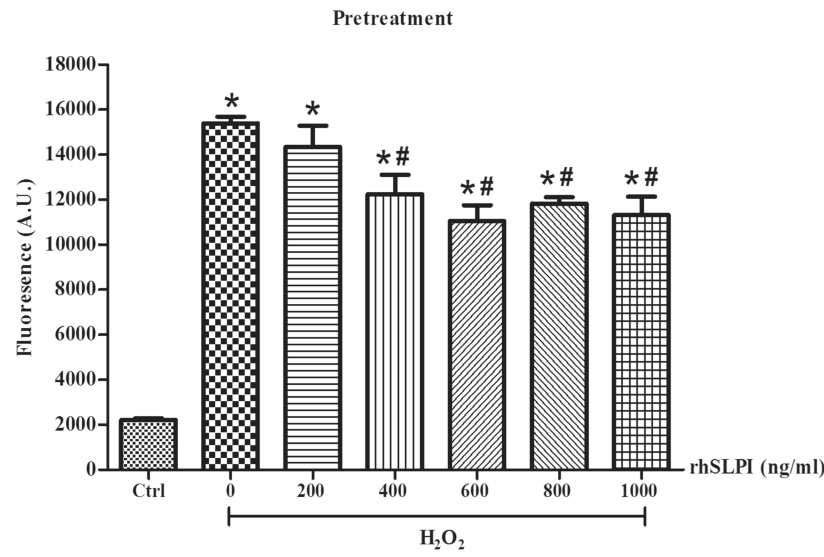

B

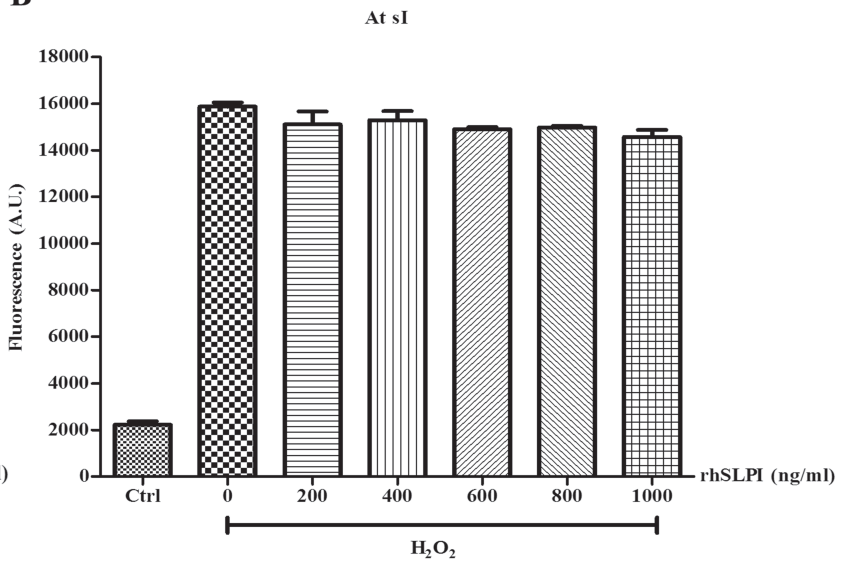

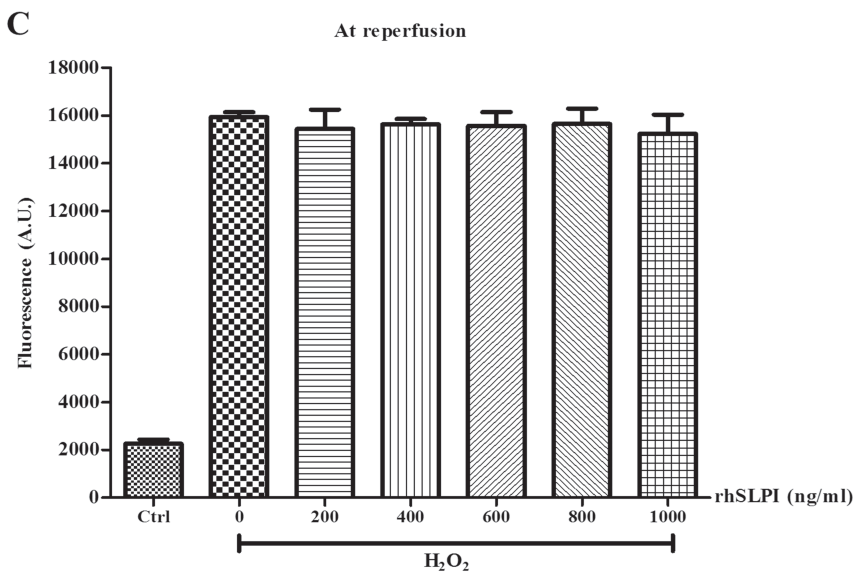

Figure 7: Determination of the cellular ROS level in rhSLPI-treated $\mathrm{H} 9 \mathrm{c} 2$ cells challenged with $\mathrm{H}_{2} \mathrm{O}_{2}$. $\mathrm{H} 9 \mathrm{c} 2$ cells were incubated with carboxy$\mathrm{H} 2 \mathrm{DCFDA}$. After incubation, $\mathrm{H}_{2} \mathrm{O}_{2}$ was applied to all groups of $\mathrm{H} 9 \mathrm{c} 2$ cells and the cellular ROS level was determined spectrophotometrically. Each bar graph represents means \pm S.E.M for three experiments. ${ }^{*} p<0.05$ vs control cell (ANOVA) and \# $p<0.05$ among $\mathrm{H}_{2} \mathrm{O}_{2}$ treated group (ANOVA).

\section{Treatment of rhSLPI decreases intracellular ROS level in H9c2 cells}

To further investigate the cardio-protective effects of rhSLPI treatment during I/R injury, we next determined the cellular ROS level after treating H9c2 cells with various concentrations of rhSLPI, followed by incubating the cells for $1 \mathrm{~h}$. These cells were then challenged with $\mathrm{H}_{2} \mathrm{O}_{2}$.

The result showed that the $\mathrm{H}_{2} \mathrm{O}_{2}$, which applied to the $\mathrm{H} 9 \mathrm{c} 2$ cells, resulted in an increased cellular ROS level in the H9c2 cells when compared to the normal condition $(15,395 \pm 508.1$ A.U. vs $2214 \pm 67.15$ A.U.). The treatment of $\mathrm{H} 9 \mathrm{c} 2$ cells by $400 \mathrm{ng} / \mathrm{ml}, 600 \mathrm{ng} / \mathrm{ml}, 800 \mathrm{ng} / \mathrm{ml}$, and 1000 ng/ml rhSLPI (12,238 \pm 1511 A.U., 11,057 \pm 1212 A.U., 11,834 \pm 474.9 A.U., and $11,312 \pm 1420$ A.U.) significantly reduced the cellular ROS level in the $\mathrm{H} 9 \mathrm{c} 2$ cells after $\mathrm{H}_{2} \mathrm{O}_{2}$ challenging when compared to the untreated H9c2 cells $(15,395 \pm$
508.1 A.U.). It is noteworthy that rhSLPI at $400 \mathrm{ng} / \mathrm{ml}$ was the lowest concentration that significantly reduced the ROS production. The rhSLPI at $200 \mathrm{ng} / \mathrm{ml}$ produced no noticeable reduction in ROS production (Figure 7A). However, treatment of the rhSLPI at the onset of ischemia (Figure 7B), as well as at the onset of reperfusion (Figure 7C), did not significantly reduced intracellular ROS production in $\mathrm{H} 9 \mathrm{c} 2$ cells.

\section{Pretreatment of rhSLPI activated Akt phosphorylation and attenuated p38 MAPK activation}

To determine the cellular signaling in response to rhSLPI in the H9c2 cells during sI/R injury, the H9c2 cells were pretreated with various concentrations of rhSLPI for 24 
A

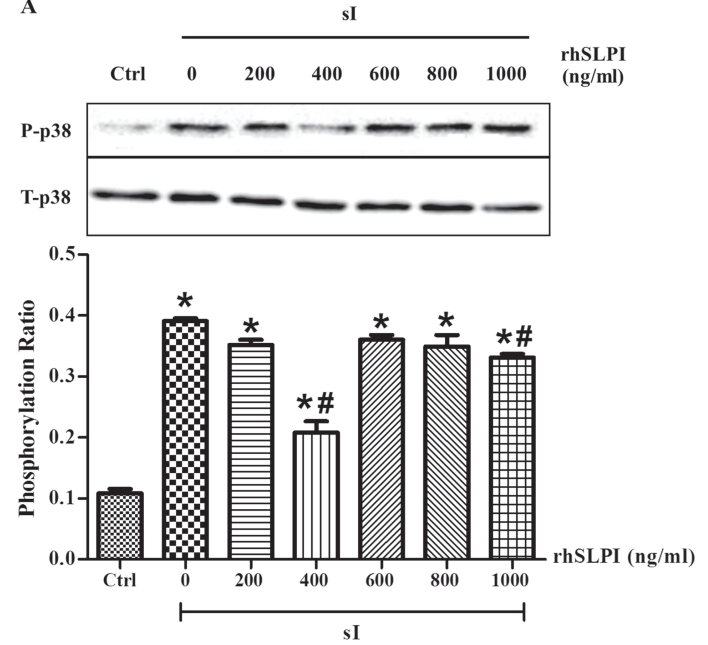

B

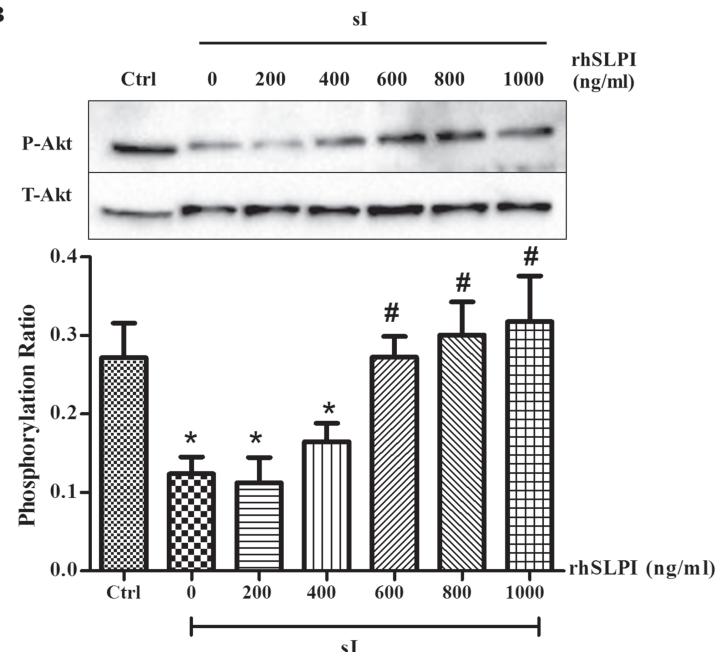

Figure 8: Effects of rhSLPI treatment in H9c2 cells on p38 MAPK and Akt activation during simulated ischemia. A and B show H9c2 cells treated with various concentrations of rhSLPI and stimulated with sl. The cells were then harvested, and p38 MAPK (p-P38) and Akt (p-Akt) activation were determined by Western Blot. Each bar graph represents fold phosphorylation of $\mathrm{p} 38$ MAPK and Akt for each of the three experiments. ${ }^{*} p<0.05$ vs control of each group (ANOVA). $\# p<0.05 \mathrm{vs}$ sl group.

$\mathrm{h}$ at each concentration, before switching to sI. Western blotting was performed for analyzing the phosphorylation of $\mathrm{p} 38$ MAPK and Akt.

The result showed that p38 MAPK was strongly phosphorylated in response to simulated ischemia. Pretreatment with rhSLPI at $400 \mathrm{ng} / \mathrm{ml}$ and $1000 \mathrm{ng} /$ ml significantly reduced p38 MAPK phosphorylation (Figure 8A); rhSLPI at other concentrations tested had no noticeable effect. We also found that treatment of rhSLPI at concentrations in the range $600-1000 \mathrm{ng} / \mathrm{ml}$ prior sI significantly increased the Akt phosphorylation as compared to the sI group (Figure 8B).

\section{Discussion}

Ischemic heart disease is known as a major cause of death for people worldwide [1, 2]. The most effective way to treat myocardial ischemia is reperfusion, but reperfusion itself can cause a cardiomyocyte injury called myocardial ischemia/reperfusion (I/R) injury [25]. One of the key mechanisms of cardiac cell death during myocardial $\mathrm{I} / \mathrm{R}$ injury is over-production of protease enzymes secreted from infiltrated leukocytes as well as cardiac cell lysis $[5-7,26]$. These protease enzymes cause cellular injury, especially to cells located within and around the ischemic area, which could expand the area of injury. Therefore, prevention or attenuation of the protease enzyme activity caused by myocardial $I / R$ injury is one of the most promising clinical targets.
Theeffectsofproteaseinhibitorshavebeen investigated over the past year on post-ischemic inflammation. Cowan B. et al. reported that elafin, a serine elastase inhibitor, attenuates post-cardiac transplant coronary arteriopathy and reduces myocardial necrosis in rabbits after heterotopic cardiac transplantation [27]. The results from Tiefenbacher C.P. et al. showed that treatment with two specific elastase inhibitors, elafin and ICI 200880, in perfused rat heart models of myocardial stunning and MI significantly improved myocardial function and reduced areas at risk of the heart [28]. In addition, inhibition of neutrophils or inhibition of the protease enzymes secreted from neutrophils also has cardio-protective effects on myocardial $\mathrm{I} / \mathrm{R}$ injury [29, 30]. Hoffmeyer M.R. et al. investigated the effects of PR-39, a potent neutrophil inhibitor, in a murine model of myocardial I/R injury [29]. They found that reperfusion following pretreatment with the peptide PR-39 significantly reduced myocardial infarction by inhibiting leukocyte recruitment into inflamed tissue in a murine model of myocardial I/R [29]. Ueno M. et al. found that ONO-5046 Na, a PMN elastase inhibitor, reduces ischemia/reperfusion injury in heart transplantation by inhibiting of PMN elastase and inflammatory cytokines [30]. Among protease inhibitors, secretory leukocyte protease inhibitors (SLPIs) seem to be the broadest and most promising option for myocardial I/R injury [31]. Lentsch A.B. et al. identified and characterized the effects of SLPI during hepatic ischemia and reperfusion in mice [32]. They found that SLPI reduced liver and lung damage and diminished neutrophil accumulation by 
reduced serum levels of tumor necrosis factor (TNF)-a, CXC chemokine macrophage inflammatory protein (MIP)-2 and suppressed activation of transcription factor NF-kB in the liver [32]. These reports highlight the importance of protease inhibition during I/R injury in terms of preventing protease activity secreted by infiltrated inflammatory cells. However, the ability of these protease inhibitors to inhibit the protease activity from lysed cardiac cells during $I / R$ injury has never been investigated.

In 2008, Schneeberger S. et al. reported for the first time the protective effects of SLPI on cardiac transplantation in mice [13]. They found that exogenous rhSLPI added in a cold-preservative buffer improved cardiac score of SLPI-/after heart transplantation [13]. In addition, exogenous rhSLPI reduced the expression of protease enzymes and pro-inflammatory cytokines in transplanted mice [13]. Given these phenomena, we hypothesized that SLPI could prevent or attenuate the degree of cardiac cell death and cell injury caused by I/R injury and SLPI could be a promising clinical target for myocardial $\mathrm{I} / \mathrm{R}$ injury. We previously reported that pretreatment of rhSLPI in isolated adult rat ventricular myocytes as well as perfused in whole heart prior to ischemia, could significantly reduce cell death, injury, and reduced infarct size [33]. In addition, rhSLPI treatment could reduce ischemia-induced vascular endothelial cell death and injury [34]. However, the SLPI expression level in the H9c2 cells in our experiments was very low (Figure 1a). Therefore, in our study, the overexpression of SLPI in H9c2 cells was a strategy used for determining the biological and physiological roles of this overexpression against ischemia/reperfusion injury. The stable cardiac cell line and constitutively expressed human SLPI were generated from the cardiac myoblast (H9c2) cell line. Our study is the first to generate stable cardiac cells overexpressing SLPI. The overexpression of rhSLPI did not change the H9c2 cell lines' biological properties including cell proliferation and cell growth, the time for population doubling, the cell morphology compared to the mock transfected cells, or the parental cells. However, the SLPI secreted from the overexpressing cells manifested serine protease inhibitory activity.

Our study demonstrated for the first time that the overexpression of rhSLPI in the cardiac cell lines has a cardioprotective effect against an in vitro ischemia/ reperfusion, by reducing cell death, cell injury, and increasing the phosphorylation of Akt.

There have also been other studies on the overexpression of rhSLPI in other cells including macrophages, RAW264.7 cells, endothelial cells, and in the brain of spontaneously hypertensive rats (SHR) [35-38]. When Ding A. et al. produced the HeN.C2 cell lines (macrophage cell lines) overexpressing SLPI [38], they found that the overexpression of SLPI decreases the sensitivity of macrophages to LPS but not their ability to respond to LPS by blocking the formation of LPS-sCD14 complexes [38]. Odaka C. et al. generated RAW264.7 cells overexpressing rhSLPI and found that the overexpression of SLPI in RAW264.7 cells suppresses TNF-a production in response to apoptotic cells [36]. Henriksen P.A. et al. constructed an adenovirus containing rhSLPI proteins and transfected it into macrophages and HUVEC cells [37]. They found that the overexpression of rhSLPI in those cell types reduces the pro-inflammatory cytokine production after TNF-a, LPS, and oxidized LDL stimulating [37]. In addition, the overexpression of SLPI in the brains of spontaneously hypertensive rats (SHR) resulted in a reduction in ischemic lesions and significantly improved the functional outcome of the brain [35].

Although the ectopic expression of rhSLPI in cardiac cells provides some useful information, it may not be practical as a clinical intervention, since the overexpression implies applying gene therapy. Given this, the more practical model is to use SLPI to treat patients with I/R injury. In our study, the cardiac cell lines were treated with the rhSLPI under three conditions: prior to ischemia/reperfusion (pre-treatment), at the onset of ischemia, and at the onset of reperfusion. The results showed that treatment with rhSLPI prior to ischemia/ reperfusion shows cardio-protective effects. The in vitro treatment with $400 \mathrm{ng} / \mathrm{ml} \mathrm{rhSLPI}$ prior to the onset of ischemia is the lowest concentration to give most effective cardioprotection. However, a greater concentration of rhSLPI (2000 $\mathrm{ng} / \mathrm{ml}$ in the dose optimization step, figure 5) could not provide a protective effect, which could possibly cause cellular toxicity at this concentration. There have been previous studies investigating the effects of treatment by rhSLPI on many cell types. Treatment of adult neural stem cells (NSC) with rhSLPI increased cell proliferation and differentiation of NSC towards oligodendrocytes by an upregulation of cyclin D1 and a suppression of the cell differentiation regulator, HES1 [39]. The incubation of human neutrophils treated with rhSLPI resulted in the prevention of the neutrophils' apoptosis [40]. McGarry N. et al. showed that the rhSLPI inhibited a TNF- $\alpha$ induced caspase-3 activation and DNA degradation associated with apoptosis in monocytes, demonstrating the antiapoptotic effect of rhSLPI in U937 cells and peripheral blood monocytes [41]. Information from other studies of other cell types also suggests the anti-apoptotic roles of rhSLPI treatment. However, in this study, determination of cell viability was performed using MTT assay, which might not provide an explanation for cellular apoptosis 
and is considered a limitation of this study. Therefore, determination of apoptosis, by Anexin $\mathrm{V}$ staining or TUNEL assay, should be performed.

Reactive oxygen species (ROS) plays a major role in $\mathrm{I} / \mathrm{R}$ induced cell death and cell injury during myocardial ischemia [42, 43]. ROS induces cellular damage via many pathways including direct damage to cell membranes and proteins or indirect damage through the activation of pro-apoptotic pathways, and recruitment of the inflammatory cells [42, 44-47]. Besides acting as an antiprotease, the rhSLPI also has other important biological properties; in particular, it increases the glutathione levels in the lung as reported by Gillissen A. et al. [15]. This suggests that the rhSLPI may be particularly well suited for therapy in diseases characterized by an excess of both the serine proteases and the oxidants [15]. The previous study from Masterson C.H. et al. found that the overexpression of rhSLPI together with glutathione Peroxidase-3 (GPX-3) reduces inflammation and oxidantinduced lung injury [48]. Since ROS plays a major role on I/R injury, and SLPI acts as the artificial antioxidant, the cellular ROS generation in the stable cells overexpressing SLPI and the treatment of rhSLPI on the H9c2 cells in sI/R were investigated. Our results showed that the rhSLPI overexpression and pretreatment of rhSLPI (but not during ischemia and at the onset of reperfusion) decreased cellular ROS generation during the $\mathrm{H}_{2} \mathrm{O}_{2}$ challenging. This is the first evidence showing the overexpression of rhSLPI in H9c2 cells. We have also demonstrated that treating normal H9c2 cells with rhSLPI reduced the cellular ROS generation in cardiac cells, and can be considered an effective treatment of $\mathrm{H} 9 \mathrm{c} 2$ cells in sI/R. As previously mentioned, the rhSLPI increases the glutathione levels in the lung which leads to reduced ROS levels. Thus, the reduction of ROS in our study, which reduced cell death and cell injury in $\mathrm{H} 9 \mathrm{c} 2$ cells overexpressing rhSLPI or in the treatment with rhSLPI in H9c2 cells, may be due to an increase of the glutathione and not due to the direct effect of rhSLPI on the ROS scavenging. Further research on the cellular mechanisms by which the rhSLPI reduces intracellular ROS levels as well as the effect of rhSLPI treatment on glutathione levels or expression need to be further investigated.

Myocardial ischemia/reperfusion injury is a potent stimulant of p38 MAPK activation, which leads to myocardial cell death and myocardial cell injury [14, 16-20]. Given that the overexpression and the treatment of rhSLPI in the H9c2 cells reduced myocardial cell death and myocardial cell injury in an in vitro ischemia/reperfusion, we hypothesized that the decrease in myocardial cell death and myocardial cell injury by overexpression and successful treatment of the H9c2 cells with rhSLPI resulted from an attenuation of $\mathrm{p} 38 \mathrm{MAPK}$ activation. These results showed that there is no significant difference in p38 MAPK phosphorylation in the SLPI overexpressing cells, and the treatment by rhSLPI, at concentrations of 400-1000 ng/ $\mathrm{ml}$, attenuated the p38 MAPK activation. This indicates that it was the attenuation of p38 MAPK activation that produced the cardioprotective effect of the rhSLPI treatment. However, the mechanistic explanation of rhSLPI on p38 MAPK could not fully be addressed without having a p38 MAPK inhibitor in the experiment, and this is considered a limitation of this study. Although p38 MAPK is the predominant kinase that well defined to be activated and aggravate the cardiac cell death and injury, the activation of cell survival kinase p44/p42 MAPK (Erk) should also be performed, since it has been known that Erk phosphorylation could reduce cell death and injury. This point is considered a limitation of this study, and suggest for being further investigated.

Protein kinase B (PKB), also known as Akt, is a serine/ threonine protein kinase that plays a role in the cell survival pathway [21-24]. Activation of the Akt-dependent signaling prevents the cardiomyocyte apoptosis, leading to attenuation of the myocardial I/R injury [21-24]. Therefore, we hypothesized that the overexpression and the treatment of rhSLPI in H9c2 cells could possibly activate the Akt phosphorylation during sI/R injury. The results showed that the simulated ischemia significantly activated the Akt phosphorylation in the rhSLPI overexpressing cell, as well as in the pre-treatment of rhSLPI prior to sI. However, the mechanistic explanation of rhSLPI in Akt signaling could not fully be addressed without having an Akt inhibitor in the experiment, and this point is considered a limitation of this study.

There are several issues which can be considered as limitations of our study. The overexpression of rhSLPI in the H9c2 cells may not be closely related to real physiological settings in the intact heart. Even though the H9c2 cells have biological properties similar to cardiomyocyte, these cells do not show the electrophysiological property $[49,50]$. Therefore, the more relevant models, such as the overexpression of rhSLPI in the primary culture of isolated ventricular myocytes, or in the intact heart, will provide more functional data, as these are closer to the real physiological events in the heart, which could lead to a more reliable interpretation. Moreover, the ectopic expression of rhSLPI in the cardiac cells might be artificial and not practical in terms of therapy, as the overexpression implies gene therapy in the real clinical setting. Therefore, the more practical model is to use rhSLPI as a drug for treatment of myocardial ischemia patients. The treatment 
by rhSLPI has some aspects similar to the overexpression of rhSLPI in the H9c2 cells because both conditions have a higher concentration of rhSLPI from the basal level. Moreover, an in vitro simulated ischemia/reperfusion model might not well represent the real physiological phenomenon occurring in a myocardial ischemia/ reperfusion. Therefore, the most appropriate experimental strategy, which could be a model for drug treatment, is an in vivo treatment of rhSLPI in animal model. Furthermore, in this study, the cardioprotective effect of rhSLPI could be observed only in the pretreatment condition. Therefore, based on the present study, it might be too early to make a conclusion regarding whether rhSLPI has translational potential. However, this study could provide important evidence about the cardioprotection of rhSLPI as well as providing a mechanistic explanation for the therapeutic potential of rhSLPI. Therefore, the more physiological/ cardiac relevant models, such as an in vitro study in isolated adult cardiomyocytes, an ex vivo study of isolated perfused heart (with ischemia/reperfusion procedure), and an in vivo study of ischemia/reperfusion injury, need to be intensively investigated. Determining the effects of rhSLPI on cardiac function, infarct size, as well as the incidence of arrhythmias, when administered at various times during $\mathrm{I} / \mathrm{R}$ periods in an in vivo model could provide useful data before moving forward to clinical trials.

Acknowledgments: This work was supported by The Royal Golden Jubilee Ph.D Program [grant number PHD/0043/2555; join funding between the Thailand Research Fund and Naresuan University] and National Research Council of Thailand (NRCT)-Naresuan University [grant number R2558B06]. Moreover, we would like to thank the Newton Fund in cooperation with The Royal Golden Jubilee Ph.D Program for providing PhD placement scholarship for EP, SK. We would like to thank Mr. Roy Morien of the Naresuan University Language Center for his editing assistance and advice on English expression in this document.

Conflicts of Interest: The authors declare no conflict of interest.

\section{References}

1. Mozaffarian D, Benjamin EJ, Go AS, Arnett DK, Blaha MJ, Cushman M, et al. Heart Disease and Stroke Statistics-2016 Update: A Report From the American Heart Association. Circulation. 2016;133(4):e38-360.
2. World Health Statistics 2008 [Internet]. 2008 [cited 1 August 2016]. Available from: http://www.who.int/entity/whosis/ whostat/EN_WHS08_Full.pdf.

3. Jennings RB, Reimer KA. The cell biology of acute myocardial ischemia. Annual review of medicine. 1991;42:225-46.

4. Yellon DM, Hausenloy DJ. Myocardial reperfusion injury. The New England journal of medicine. 2007;357(11):1121-35.

5. Boudoulas KD, Hatzopoulos AK. Cardiac repair and regeneration: the Rubik's cube of cell therapy for heart disease. Disease models \& mechanisms. 2009;2(7-8):344-58.

6. Epelman S, Liu PP, Mann DL. Role of innate and adaptive immune mechanisms in cardiac injury and repair. Nature reviews Immunology. 2015;15(2):117-29.

7. Jordan JE, Zhao ZQ, Vinten-Johansen J. The role of neutrophils in myocardial ischemia-reperfusion injury. Cardiovascular research. 1999;43(4):860-78.

8. Schneeberger S, Brandacher G, Mark W, Amberger A, Margreiter R. Protease Inhibitors as a Potential Target in Modulation of Postischemic Inflammation. Drug news \& perspectives. 2002;15(9):568-74.

9. Bouchard D, Morisset D, Bourbonnais Y, Tremblay GM. Proteins with whey-acidic-protein motifs and cancer. The Lancet Oncology. 2006;7(2):167-74.

10. Majchrzak-Gorecka M, Majewski P, Grygier B, Murzyn K, Cichy J. Secretory leukocyte protease inhibitor (SLPI), a multifunctional protein in the host defense response. Cytokine \& growth factor reviews. 2016;28:79-93.

11. Moreau T, Baranger K, Dade S, Dallet-Choisy S, Guyot N, Zani ML. Multifaceted roles of human elafin and secretory leukocyte proteinase inhibitor (SLPI), two serine protease inhibitors of the chelonianin family. Biochimie. 2008;90(2):284-95.

12. Doumas S, Kolokotronis A, Stefanopoulos P. Anti-inflammatory and antimicrobial roles of secretory leukocyte protease inhibitor. Infection and immunity. 2005;73(3):1271-4.

13. Schneeberger S, Hautz T, Wahl SM, Brandacher G, Sucher R, Steinmassl 0 , et al. The effect of secretory leukocyte protease inhibitor (SLPI) on ischemia/reperfusion injury in cardiac transplantation. American journal of transplantation : official journal of the American Society of Transplantation and the American Society of Transplant Surgeons. 2008;8(4):773-82.

14. Kumphune S, Surinkaew S, Chattipakorn SC, Chattipakorn N. Inhibition of $\mathrm{p} 38$ MAPK activation protects cardiac mitochondria from ischemia/reperfusion injury. Pharmaceutical biology. 2015;53(12):1831-41.

15. Gillissen A, Birrer P, McElvaney NG, Buhl R, Vogelmeier C, Hoyt RF, Jr., et al. Recombinant secretory leukoprotease inhibitor augments glutathione levels in lung epithelial lining fluid. Journal of applied physiology (Bethesda, Md : 1985). 1993;75(2):825-32.

16. Kaiser RA, Lyons JM, Duffy JY, Wagner CJ, McLean KM, O’Neill TP, et al. Inhibition of p38 reduces myocardial infarction injury in the mouse but not pig after ischemia-reperfusion. American journal of physiology Heart and circulatory physiology. 2005;289(6):H2747-51.

17. Gorog DA, Tanno M, Cao X, Bellahcene M, Bassi R, Kabir AM, et al. Inhibition of p38 MAPK activity fails to attenuate contractile dysfunction in a mouse model of low-flow ischemia. Cardiovascular research. 2004;61(1):123-31.

18. Kumphune S, Bassi R, Jacquet S, Sicard P, Clark JE, Verma $S$, et al. A chemical genetic approach reveals that p38alpha 
MAPK activation by diphosphorylation aggravates myocardial infarction and is prevented by the direct binding of SB203580. The Journal of biological chemistry. 2010;285(5):2968-75.

19. Ma XL, Kumar S, Gao F, Louden CS, Lopez BL, Christopher $\mathrm{TA}$, et al. Inhibition of p38 mitogen-activated protein kinase decreases cardiomyocyte apoptosis and improves cardiac function after myocardial ischemia and reperfusion. Circulation. 1999;99(13):1685-91.

20. Kumphune S, Chattipakorn S, Chattipakorn N. Role of p38 inhibition in cardiac ischemia/reperfusion injury. European journal of clinical pharmacology. 2012;68(5):513-24.

21. Yu L, Li F, Zhao G, Yang Y, Jin Z, Zhai M, et al. Protective effect of berberine against myocardial ischemia reperfusion injury: role of Notch1/Hes1-PTEN/Akt signaling. Apoptosis : an international journal on programmed cell death. 2015;20(6):796-810.

22. Mullonkal CJ, Toledo-Pereyra LH. Akt in ischemia and reperfusion. Journal of investigative surgery : the official journal of the Academy of Surgical Research. 2007;20(3):195203.

23. Fujio Y, Nguyen T, Wencker D, Kitsis RN, Walsh K. Akt promotes survival of cardiomyocytes in vitro and protects against ischemia-reperfusion injury in mouse heart. Circulation. 2000;101(6):660-7.

24. Armstrong SC. Protein kinase activation and myocardial ischemia/reperfusion injury. Cardiovascular research. 2004;61(3):427-36.

25. Yellon DM, Hausenloy DJ. Myocardial reperfusion injury. N Engl J Med. 2007;357(11):1121-35.

26. Rohrbach S, Troidl C, Hamm C, Schulz R. Ischemia and reperfusion related myocardial inflammation: A network of cells and mediators targeting the cardiomyocyte. IUBMB life. 2015;67(2):110-9.

27. Cowan B, Baron O, Crack J, Coulber C, Wilson GJ, Rabinovitch M. Elafin, a serine elastase inhibitor, attenuates post-cardiac transplant coronary arteriopathy and reduces myocardial necrosis in rabbits afer heterotopic cardiac transplantation. The Journal of clinical investigation. 1996;97(11):2452-68.

28. Tiefenbacher CP, Ebert M, Niroomand F, Batkai S, Tillmanns $\mathrm{H}$, Zimmermann R, et al. Inhibition of elastase improves myocardial function after repetitive ischaemia and myocardial infarction in the rat heart. Pflugers Archiv : European journal of physiology. 1997;433(5):563-70.

29. Hoffmeyer MR, Scalia R, Ross CR, Jones SP, Lefer DJ. PR-39, a potent neutrophil inhibitor, attenuates myocardial ischemiareperfusion injury in mice. American journal of physiology Heart and circulatory physiology. 2000;279(6):H2824-8.

30. Ueno M, Moriyama Y, Toda R, Yotsumoto G, Yamamoto H, Fukumoto Y, et al. Effect of a neutrophil elastase inhibitor (ONO$5046 \mathrm{Na}$ ) on ischemia/reperfusion injury using the left-sided heterotopic canine heart transplantation model. The Journal of heart and lung transplantation : the official publication of the International Society for Heart Transplantation. 2001;20(8):889-96.

31. Schneeberger S, Brandacher G, Mark W, Amberger A, Margreiter R. Protease inhibitors as a potential target in modulation of postischemic inflammation. Drug News Perspect. 2002;15:568-74.

32. Lentsch AB, Yoshidome H, Warner RL, Ward PA, Edwards MJ. Secretory leukocyte protease inhibitor in mice regulates local and remote organ inflammatory injury induced by hepatic ischemia/reperfusion. Gastroenterology. 1999;117(4):953-61.

33. Prompunt E, Sanit J, Barrère-Lemaire S, Nargeot J, Noordali $\mathrm{H}$, Madhani M, et al. Cardio-protective effects of secretory leukocyte protease inhibitor (SLPI) against myocardial ischemia/reperfusion injury. Experimental and therapeutic medicine. 2018; In Press.

34. Nernpermpisooth N, Prompunt E, Kumphune S. An in vitro endothelial cell protective effect of secretory leukocyte protease inhibitor against simulated ischaemia/ reperfusion injury. Experimental and therapeutic medicine. 2017;14(6):5793-800.

35. Wang X, Li X, Xu L, Zhan Y, Yaish-Ohad S, Erhardt JA, et al. Upregulation of secretory leukocyte protease inhibitor (SLPI) in the brain after ischemic stroke: adenoviral expression of SLPI protects brain from ischemic injury. Molecular pharmacology. 2003;64(4):833-40.

36. Odaka C, Mizuochi T, Yang J, Ding A. Murine macrophages produce secretory leukocyte protease inhibitor during clearance of apoptotic cells: implications for resolution of the inflammatory response. Journal of immunology (Baltimore, Md : 1950). 2003;171(3):1507-14.

37. Henriksen PA, Hitt M, Xing Z, Wang J, Haslett C, Riemersma RA, et al. Adenoviral gene delivery of elafin and secretory leukocyte protease inhibitor attenuates NF-kappa B-dependent inflammatory responses of human endothelial cells and macrophages to atherogenic stimuli. Journal of immunology (Baltimore, Md : 1950). 2004;172(7):4535-44.

38. Ding A, Thieblemont N, Zhu J, Jin F, Zhang J, Wright S. Secretory leukocyte protease inhibitor interferes with uptake of lipopolysaccharide by macrophages. Infection and immunity. 1999;67(9):4485-9.

39. Mueller AM, Pedre X, Stempfl T, Kleiter I, Couillard-Despres $\mathrm{S}$, Aigner $\mathrm{L}$, et al. Novel role for SLPI in MOG-induced EAE revealed by spinal cord expression analysis. Journal of neuroinflammation. 2008;5:20.

40. Subramaniyam D, Hollander C, Westin U, Erjefalt J, Stevens T, Janciauskiene S. Secretory leukocyte protease inhibitor inhibits neutrophil apoptosis. Respirology. 2011;16(2):300-7.

41. Niamh McGarry CMG, Noel G. McElvaney, Sinéad Weldon, and Clifford C. Taggart, . The Ability of Secretory Leukocyte Protease Inhibitor to Inhibit Apoptosis in Monocytes Is Independent of Its Antiprotease Activity. Journal of Immunology Research. 2015;2015(Article ID 507315):6.

42. Hoffman JW, Jr., Gilbert TB, Poston RS, Silldorff EP. Myocardial reperfusion injury: etiology, mechanisms, and therapies. The journal of extra-corporeal technology. 2004;36(4):391-411.

43. Raedschelders K, Ansley DM, Chen DD. The cellular and molecular origin of reactive oxygen species generation during myocardial ischemia and reperfusion. Pharmacology \& therapeutics. 2012;133(2):230-55.

44. Lucchesi BR. Myocardial ischemia, reperfusion and free radical injury. The American journal of cardiology. 1990;65(19):14i-23i.

45. Venardos KM, Perkins A, Headrick J, Kaye DM. Myocardial ischemia-reperfusion injury, antioxidant enzyme systems, and selenium: a review. Current medicinal chemistry. 2007;14(14):1539-49.

46. Hausenloy DJ, Yellon DM. Myocardial ischemia-reperfusion injury: a neglected therapeutic target. The Journal of clinical investigation. 2013;123(1):92-100. 
47. Ferrari R, Agnoletti L, Comini L, Gaia G, Bachetti T, Cargnoni A, et al. Oxidative stress during myocardial ischaemia and heart failure. European heart journal. 1998;19 Suppl B:B2-11.

48. C.H. Masterson DPOT, J.G. Laffey., editor Over Expression of Secretory Leukocyte Protease Inhibitor (SLPI) And Glutathione Peroxidase-3 (GPX3) Attenuate Inflammation And OxidantMediated Pulmonary Epithelial Injury. American Thoracic Society 2012 International Conference; 2012; San Francisco, California.
49. Kimes BW, Brandt BL. Properties of a clonal muscle cell line from rat heart. Exp Cell Res. 1976;98(2):367-81.

50. Hescheler J, Meyer R, Plant S, Krautwurst D, Rosenthal W, Schultz G. Morphological, biochemical, and electrophysiological characterization of a clonal cell ( $\mathrm{H} 9 \mathrm{c} 2)$ line from rat heart. Circulation research. 1991;69(6):1476-86. 